\title{
Synthesis and properties of new amphoteric poly(amidoamine) dendrimers
}

\author{
X. C. Peng ${ }^{*}$, X. H. Peng' ${ }^{2}$ S. M. Liu' ${ }^{2}$ J. Q. Zhao ${ }^{2}$ \\ ${ }^{1}$ Department of Chemistry and Chemical Engineering, Jishou University, Hunan 416000, China \\ ${ }^{2}$ College of Materials Science and Engineering, South China University of Technology, Guangzhou 510640, China
}

Received 30 March 2009; accepted in revised form 26 May 2009

\begin{abstract}
A series of new amphoteric dendrimers have been synthesized by attaching dimethylbenzylaminoethyl acrylate chloride (Bz80), sodium acrylic acid (SAA) and modified polyoxyethylene (MPEO) units to a third-generation poly(amidoamine) (PAMAM) dendrimer core via Michael addition reaction. The structure of the dendrimers was confirmed by Fourier transform infrared (FTIR), proton nuclear magnetic resonance ( ${ }^{1} \mathrm{H}$ NMR), carbon 13 nuclear magnetic resonance $\left({ }^{13} \mathrm{C}\right.$ NMR) spectroscopy and by elemental analysis. Thermal stability and intrinsic viscosity were investigated. The applicable experiment exhibited the amphoteric dendrimers have high flocculation efficiency, which could be significantly improved by combining amphoteric dendrimers with polyacrylamide (PAM). The suitable mass ratio of the dendrimers and PAM was 2:3. The study would promote the use of amphoteric dendrimers as a flocculant in treating wastewater and as a new paper retention aid in papermaking.
\end{abstract}

Keywords: nanocomposites, poly(amidoamine) (PAMAM), polyoxyethylene, amphoteric dendrimers, flocculation efficiency

\section{Introduction}

Dendrimers are highly branched macromolecules possessing a large surface area to volume ratio with well-defined interior and exterior regions. A large number of terminal groups on the dendrimers, in which each round of synthesis (or 'generation') geometrically increases the number of units added, are available for further functionalization. These terminal groups influence the solubility and adhesive properties of dendrimers. These characteristics of dendrimers confer unique chemical and physical properties, which provide the impetus for further studies of this class of macromolecules [1-5].

Currently, most of PAMAM dendrimers surfacemodified by cationic $[6,7]$, anionic $[8,9]$ and PEG chain [10-12] have been used as drug delivery carrier. Allen and Polverari [13] investigated poly (propylene imine) (PPI) dendrimers as new reten- tion aids in the production of newsprint, mechanical printing grades, and boards. These dendrimers were found to be very effective retention aids for fines, dispersed extractives, and ash in papermaking. They claimed that a retention system of dendrimers could increase not only the retention rate of pulp fines and fillers but also the paper machine dehydration velocity and could effectively remove resin and plastic ropy materials. PAMAM dendrimers can also serve as flocculants for the dyeing wastewater treatment [14] and silica scale growth inhibitors that relates to industrial water treatment [15-17]. In general, these modified dendrimers are cationic or nonionic polymers. There has been little work reported on amphoteric dendrimers modification. Our previous study on the surface-modified cationic PAMAM dendrimers indicated that they had excellent performances in flocculating and 
wastewater treatment [18]. In this paper a series of new-type amphoteric dendrimers with rigid branched structure were designed. The branching molecules were prepared by attaching dimethylbenzylaminoethyl acrylate chloride, sodium acrylic acid or modified polyoxyethylene units to a thirdgeneration poly(amidoamine) dendrimer core via Michael addition reaction. MPEO was employed as a major component in the modified dendrimers because of not only its long chain which can control dendrimer molecule size with various molecule weights but also the structure which benefits for increasing flocculation bridge. A series of MPEO were prepared by the reaction of various molecule weight PEG with acrylchloride. Intrinsic viscosity, thermal stability and flocculation efficiency of the dendrimers were presented.

\section{Experimental}

\subsection{Materials}

Poly(amidoamine) (PAMAM, G3.0) dendrimer was prepared by a divergent synthesis method starting from ethylenediamine by consecutive Michael addition and ester amidation reaction. It was based on an ethylenediamine core, and branched units were composed of both methyl acrylate and ethyl- enediamine [18]. Modified polyoxyethylenes (MPEO, $M r=454,654,1054)$ were prepared according to the reported procedure [19]. Dimethylbenzylaminoethyl acrylate chloride (Bz80), sodium acrylic acid (SAA) and polyacrylamide (PAM, VN728) were commercial products and used as received. Other organic reagents employed in the investigation were analytical reagents. They were used without further purification. Poly(tetrafluoroethylene) membrane (D34mm, 3500) was obtained from Tianjing Lianxin Biotechnology Co., Ltd.

\subsection{Instruments}

${ }^{1} \mathrm{H}$ NMR and ${ }^{13} \mathrm{C}$ NMR spectra were recorded with a Bruker DRX-400 NMR spectrometer. FTIR measurements were carried out by a Nicolet MAGNA-IR 760 spectrophotometer via the $\mathrm{KBr}$ pellet method. Elemental analysis was run in an Elementer Vario EL instrument. Paper Forming Model 255 instrument (MESSMER INSTRUMENTS), Standards Paper Squeezer PNP Model (MESSMER INSTRUMENTS). TGA data were recorded with a TGA 2050, V5.4A instruments (USA). Absorbance was performed using a 721 spectrophotometer.
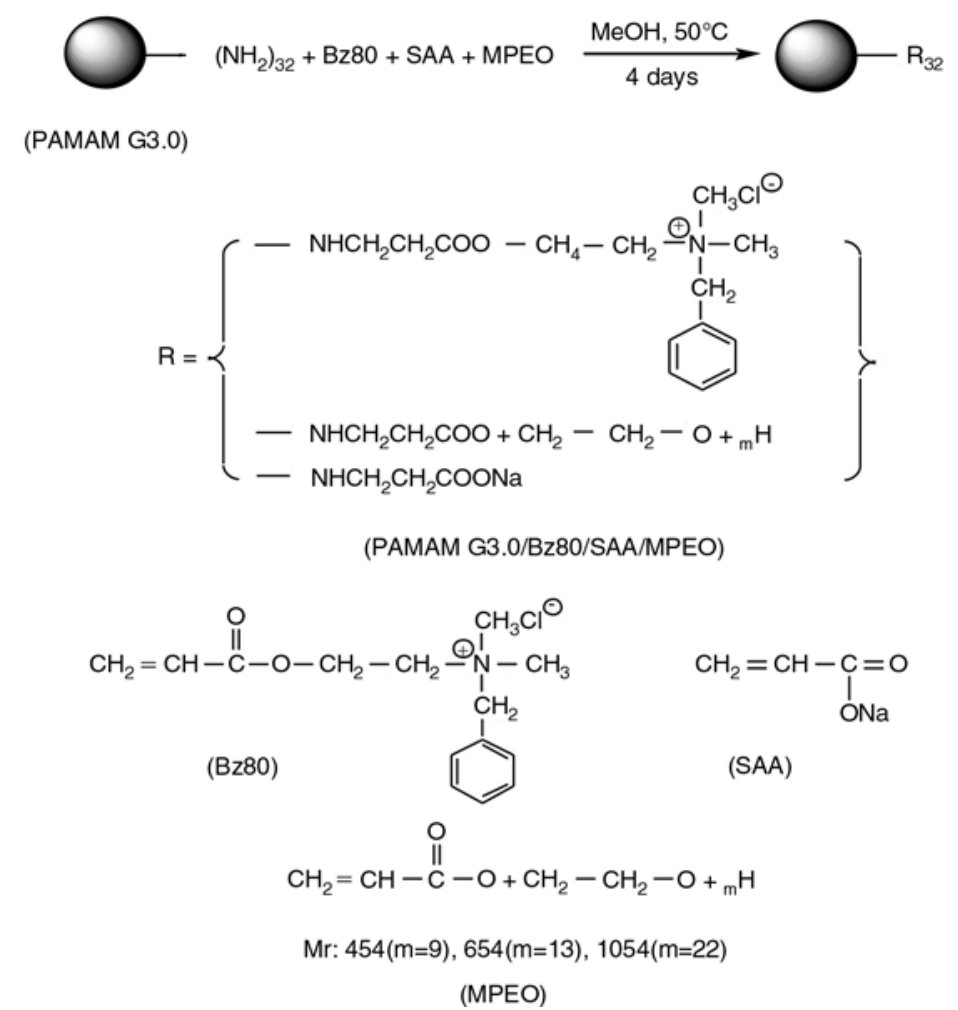

Figure 1. Surface modification of PAMAM G3.0 with Bz80, SAA and MPEO 


\subsection{Synthesis of the amphoteric PAMAM dendrimers}

PAMAM G3.0/Bz80/SAA/MPEO dendrimers were prepared according to Figure 1.

Michael addition reaction was carried out in a water bath of $50^{\circ} \mathrm{C}$ with a $500 \mathrm{ml}$, three-necked, roundbottom flask fitted with a condenser and a magnetic stirrer under nitrogen. PAMAM G3.0 dendrimer was dissolved in methanol to an appropriate concentration, and then required amounts of Bz80, SAA and MPEO were introduced to the reaction flask. After 4 day reaction insoluble materials was filtered to be removed and the residue soluble in methanol was heated under reflux in $50 \mathrm{ml}$ diethyl ether for $30 \mathrm{~min}$. The residue was filtered through a poly(tetrafluoroethylene) membrane. The product was dried in a vacuum oven at $40^{\circ} \mathrm{C}$ for $48 \mathrm{~h}$. The purified product was obtained as golden transparent ropy material. Three kinds of amphoteric PAMAM dendrimers $\left(\mathrm{P}_{1}, \mathrm{P}_{2}, \mathrm{P}_{3}\right)$ were prepared by using three different molecular weight MPEO $(\mathrm{Mr}=454$, $654,1054)$ and the yield was $72.4-78.2 \%$.

Elemental analysis was performed for $\mathrm{P}_{1}, \mathrm{P}_{2}$ and $\mathrm{P}_{3}$. Found (\%) of $\mathrm{P}_{1}$ : C 53.20, H 8.06, N 11.16; Calcd (\%) according to nominal molecular formula $\mathrm{C}_{724} \mathrm{H}_{1318} \mathrm{O}_{232} \mathrm{~N}_{132} \mathrm{Cl}_{10} \mathrm{Na}_{10}$ : C 53.77, H 8.21, N 11.43. Found (\%) of $\mathrm{P}_{2}$ : C 53.15, H 8.30, N 9.78. Calcd (\%) for $\mathrm{C}_{820} \mathrm{H}_{1510} \mathrm{O}_{280} \mathrm{~N}_{132} \mathrm{Cl}_{10} \mathrm{Na}_{10}$ : C 53.86, $\mathrm{H}$ 8.32, N 10.11; Found (\%) of $\mathrm{P}_{3}$ : C 53.87, H 8.32, $\mathrm{N}$ 7.94. Calcd (\%) for $\mathrm{C}_{1036} \mathrm{H}_{1942} \mathrm{O}_{388} \mathrm{~N}_{132} \mathrm{Cl}_{10} \mathrm{Na}_{10}$ : $\mathrm{C} 54.0, \mathrm{H} 8.49, \mathrm{~N}$ 8.02. Found and calculated results are quite consistent for the three dendrimers.

\subsection{Property measurement}

Intrinsic viscosity of the amphoteric PAMAM dendrimers was detemined by Ubbelchde viscosity measurement at $25^{\circ} \mathrm{C}$ in methanol solution. Thermal decomposition properties were conducted with a TGA 2050 in $\mathrm{N}_{2}$ atmosphere.

Flocculation efficiency of the amphoteric PAMAM dendrimers was measured as follows. A $80 \mathrm{ml}$ printing and dyeing wastewater was add in the $250 \mathrm{ml}$ beaker, and then an appropriate concentration of amphoteric PAMAM dendrimers was introduced to the container. After the mixture was magnetic stirrer at room temperature for $10 \mathrm{~min}$, the residue was filtrated. The required amounts of filter liquor (such as 1, 2, 4, 6 and $8 \mathrm{ml}$ ) was put into $50 \mathrm{ml}$ volumetric flask and diluted to scale with distilled water, then the concentration ratio was $0.02,0.04,0.08,0.12$ and 0.16 , respectively. Using 721-type spectrophotometer at $\lambda=454 \mathrm{~nm}$ measured absorbance of different concentrations to compare the effect of their flocculation.

The retention efficiency of the amphoteric PAMAM dendrimers was measured as follows. The test was operated according to a manual papermaking process with a $12.2 \mathrm{~g}$ broadleaf pulp. After pulp was put into the papermaking machinery, $0.1 \%$ retention aid was added to the pulp. Then, a manual papermaking test was carried out. The retention rate $\left(r_{p u}\right)$ was calculated from Equation (1):

$$
r_{p u}=\frac{m_{p a}}{m_{p u}} \cdot 100 \%
$$

where $m_{p a}$ is the dry mass of the paper and $m_{p u}$ is the absolute dry mass of the pulp.

\section{Results and discussion}

\subsection{Characterization of the amphoteric PAMAM dendrimers}

The obtained amphoteric PAMAM dendrimers $\mathrm{P}_{1}$, $\mathrm{P}_{2}$ and $\mathrm{P}_{3}$ have almost similar characteristic architectures. The results of FTIR, ${ }^{1} \mathrm{H}$ NMR, ${ }^{13} \mathrm{C}$ NMR of $\mathrm{P}_{3}$ are shown as the follows.

$\mathrm{P}_{3}$ (PAMAM G3.0/Bz80/SAA/MPEO ${ }_{\mathrm{Mr}=1054)}$ FTIR peaks: $(\mathrm{KBr}) \mathrm{cm}^{-1}, 2918(\mathrm{~s}), 2874(\mathrm{~s}), 1641(\mathrm{~s})$ (amide I), 1559(s) (amide II), 1457(m),1103, 950(s), 3413(s), 1724(m), 1350, 1241(m), 772, 715(s), 600(m); ${ }^{1} \mathrm{H}\left(\mathrm{D}_{2} \mathrm{O}, 400 \mathrm{MHz}\right) \delta(\mathrm{ppm}) 7.40$, 7.56, 8.15, 4.68, 3.61, 3.27-3.53, 3.20, 2.58, 2.72, $2.32, \quad 2.62-2.66, \quad 2.52 ;{ }^{13} \mathrm{C}\left(\mathrm{CDCl}_{3}, 100 \mathrm{MHz}\right)$ : $\delta(\mathrm{ppm}) 174.73,174.24,172.85,164.35,160.23$, $133.28,132.45,131.79,129.56,68.80,65.59$, $54.02,55.65,49.61,49.77,47.45,38.76,35.54$, 32.98 .

In FTIR spectrum two peaks, one at $1641 \mathrm{~cm}^{-1}$ (amide I) and the other at $1559 \mathrm{~cm}^{-1}$ (amide II), are assigned to the asymmetric stretching vibration $(\mathrm{C}=\mathrm{O})$ and the bending vibration $(\mathrm{N}-\mathrm{H})$ of $\mathrm{HN}-\mathrm{C}=\mathrm{O}$ (PAMAM dendrimers). The characteristic peaks of ether group $(\mathrm{C}-\mathrm{O}-\mathrm{C})$ are found at 1103 and $950 \mathrm{~cm}^{-1}$, respectively, which come from PEO. The peak at $3413 \mathrm{~cm}^{-1}$ due to $-\mathrm{OH}$ stretching vibration is evident. The characteristic peaks of methyl $\left(-\mathrm{N}-\mathrm{CH}_{3}\right)$, phenyl $\left(-\mathrm{C}_{6} \mathrm{H}_{5}\right)$ and chlorine 
groups $\left(-\mathrm{CH}_{3} \mathrm{Cl}^{-}\right)$are found at $1350,1241,772$, 715 and $600 \mathrm{~cm}^{-1}$. The results indicate that Bz80 and PEO chain are successfully attached to PAMAM dendrimer. In addition, the peak at $1724 \mathrm{~cm}^{-1}$ due to stretching vibration $(\mathrm{C}=\mathrm{O})$ of carboxyl groups suggests that a chain of SAA is successfully attached to the terminal groups of PAMAM G3.0 dendrimer.

${ }^{1} \mathrm{H}$ NMR and ${ }^{13} \mathrm{C}$ NMR also provide the same evidence. The single peak at $\delta 4.68 \mathrm{ppm}$ is associated with ether bond methylene protons $\left(\mathrm{CH}_{2} \mathrm{CH}_{2}-\mathrm{O}-\right)$ in ${ }^{1} \mathrm{H}$ NMR spectrum. Similarly, a series of strong peaks due to methyl groups protons appear in the region of $\delta 3.27-3.53 \mathrm{ppm}\left(-\mathrm{CH}_{3} \mathrm{Cl}^{-}\right)$and the characteristic peaks of phenyl $\left(-\mathrm{C}_{6} \mathrm{H}_{5}\right)$ appear in $\delta 7.40$, $7.56,8.15 \mathrm{ppm}$, which come from Bz80 monomer. Furthermore, the results of ${ }^{13} \mathrm{C}$ NMR spectral data are also depicted. The signals at $\delta 68.80,65.59 \mathrm{ppm}$ $\left(-\mathrm{CH}_{2} \mathrm{CH}_{2}-\mathrm{O}-\right)$ evidence the formation of the dendrimers. The characteristic peaks of the amphoteric PAMAM dendrimer appear at $\delta 133.28,132.45$, $131.79,129.56 \mathrm{ppm}$ and $\delta 49.61 \mathrm{ppm}$, which represent the $-\mathrm{C}_{6} \mathrm{H}_{5}$ and $-\mathrm{N}-\mathrm{CH}_{3}$ groups that come from Bz80 monomer. The peak values at $\delta 164.35$, 160.23 ppm represent -COO- group. The results show the amphoteric PAMAM dendrimer is synthesized.

\subsection{Intrinsic viscosity of the amphoteric PAMAM dendrimers}

In general, intrinsic viscosity of polymer was used to investigate intermolecule or intramolecule interaction beween polymer and solvent. Yamakawa [20] and Long et al. [21] investigated the hydrodynamic radius $\left(R_{\eta}\right)$ of dendrimers according to an intrinsic viscosity measurement. The molecular volume of dendrimers can be calculated from Equation (2):

$$
[\eta]=10 \pi R_{\eta}^{3} N_{A}
$$

Then the hydrodynamic radius $\left(R_{\eta}\right)$ would be (Equation (3)):

$$
R_{\eta}=\left\{\frac{3 M[\eta]}{10 \pi N_{a}}\right\}^{\frac{1}{3}}
$$

where $M$ is the molecular weight and $N_{A}$ is the Avgadro constant. Therefore, for each amphoteric
Table 1. Intrinsic viscosity [ $\eta]$ and hydrodynamic radius $R_{\eta}$ of amphoteric PAMAM dendrimers at $25^{\circ} \mathrm{C}$

\begin{tabular}{|c|c|c|c|}
\hline Dendrimers & $\begin{array}{c}\text { Molecular } \\
\text { weight } \\
\text { Mr [cal. val.] }\end{array}$ & $\begin{array}{c}\text { Intrinsic vis- } \\
\text { cosity } \\
{[\eta]\left[\mathbf{d} 1 \cdot \mathbf{g}^{-1}\right]}\end{array}$ & $\begin{array}{c}\text { Hydrody- } \\
\text { namic radius } \\
\mathbf{R}_{\boldsymbol{\eta}}[\mathbf{n m} \text { ] }\end{array}$ \\
\hline PAMAM G3.0 & $6.91 \cdot 10^{3}$ & $5.50 \cdot 10^{-2}$ & 1.82 \\
\hline $\mathrm{P}_{1}$ & $1.65 \cdot 10^{4}$ & $5.64 \cdot 10^{-2}$ & 2.44 \\
\hline $\mathrm{P}_{2}$ & $1.86 \cdot 10^{4}$ & $5.82 \cdot 10^{-2}$ & 2.57 \\
\hline $\mathrm{P}_{3}$ & $2.30 \cdot 10^{4}$ & $4.13 \cdot 10^{-2}$ & 2.46 \\
\hline
\end{tabular}

PAMAM dendrimer, hydrodynamic radius can be calculated using measured intrinsic viscosity. The date presented in Table 1 illustrates the intrinsic viscosity [ $\eta]$ and hydrodynamic radius $R_{\eta}$ of amphoteric PAMAM dendrimer.

It is clear from Table 1 that $\mathrm{P}_{2}$ has a maximum intrinsic viscosity value $\left(5.8 \cdot 10^{-2} \mathrm{~d} 1 \cdot \mathrm{g}^{-1}\right)$, and the hydrodynamic radius $R_{\eta}$ was $2.57 \mathrm{~nm} . \mathrm{P}_{3}$, however, has smaller intrinsic viscosity value $\left(4.1 \cdot 10^{-2} \mathrm{~d} 1 \cdot \mathrm{g}^{-1}\right)$ than PAMAM G3.0 dendrimer, but has larger hydrodynamic radius $R_{\eta}$. On the one hand, this may be due to the effect of some charge repulsive force interaction of the amphoteric PAMAM dendrimers. On the other hand, the length of PEO chain results in an increased twist onto the dendrimer surface. Therefore, the exterior terminal groups are main cause to affect intrinsic viscosity of dendrimers.

The amphoteric PAMAM dendrimers are watersoluble dendrimers. They are insoluble in diethyl ether, petroleum ether, but are highly soluble in carbon tetrachloride, trichloromethane.

\subsection{Thermal decomposition of the amphoteric PAMAM dendrimers}

Figure 2 shows the TGA and DTG traces of PAMAM G3.0 dendrimer, $\mathrm{P}_{1}, \mathrm{P}_{2}$ and $\mathrm{P}_{3}$ in $\mathrm{N}_{2}$. It is apparent that the thermal stepwise decomposition of the dendrimers contains signals originating from both PAMAM G3.0 dendrimer and the amphoteric PAMAM dendrimers. There is $26.7 \%$ mass loss from room temperature to $160^{\circ} \mathrm{C}$ in the TGA curve of PAMAM G3.0, mainly attributed to the decomposition of the amine-terminal groups of the peripheral dendrimer. A mass loss of $55.7 \%$ occurs in the range of $220-350^{\circ} \mathrm{C}$ and the maximal peak rate temperature $\left(T_{\max }\right)$ appears at $289^{\circ} \mathrm{C}$, assigned to decomposition of the PAMAM G3.0 dendrimer inner layer. Compared to the two-step mass loss of PAMAM G3.0, three-step mass loss trend of the amphoteric PAMAM dendrimers become more and 

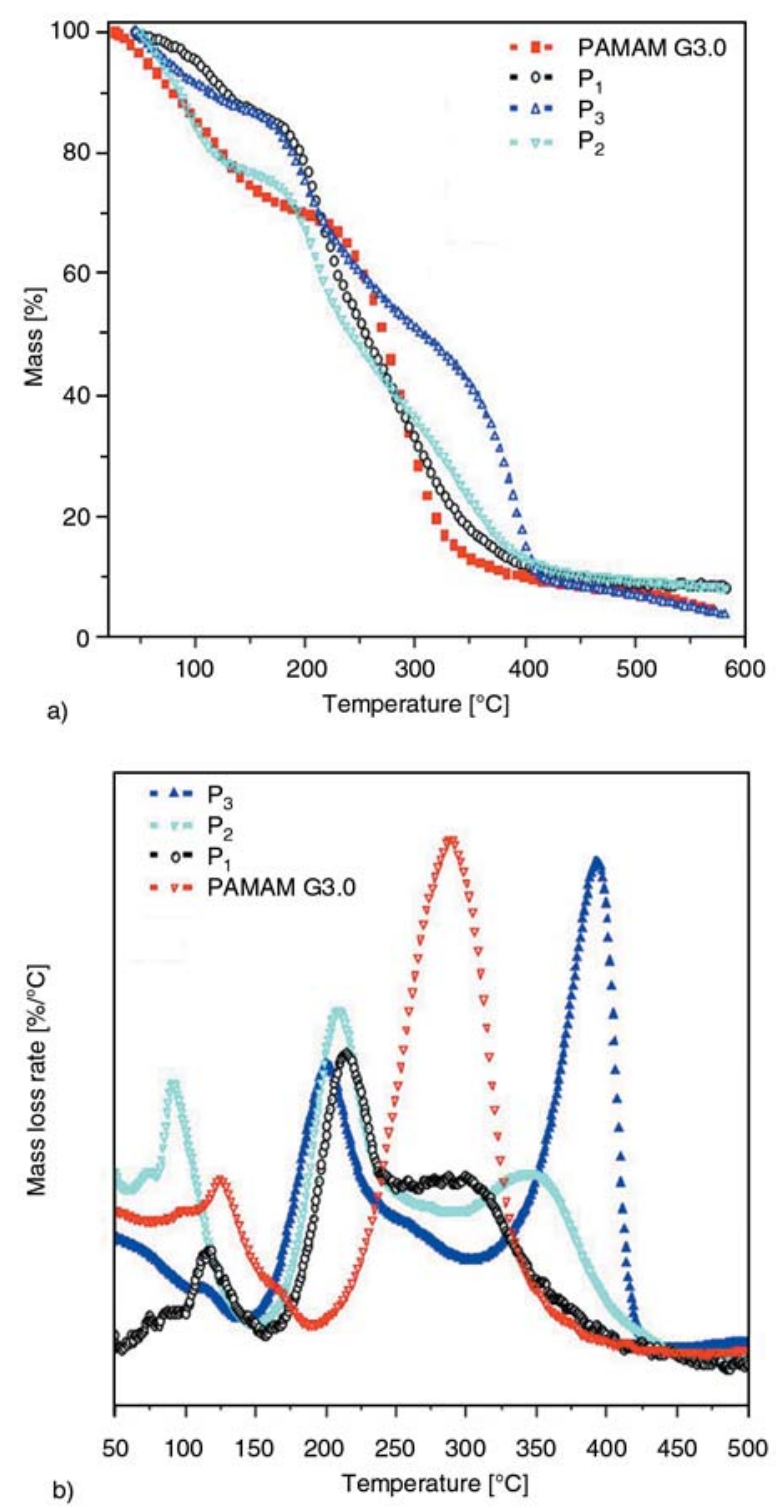

Figure 2. TGA (a) and DTG (b) curves of PAMAM G3.0, $\mathrm{P}_{1}, \mathrm{P}_{2}$ and $\mathrm{P}_{3}$

more evident with increasing molecular weight of used PEO. Three-step decomposition of $\mathrm{P}_{3}$ is apparently observed in DTG curve. The initial mass loss from room temperature to $120^{\circ} \mathrm{C}$ is $11.3 \%$, mainly attributed to the decomposition of the Bz80 and SAA chains bond of the peripheral dendrimer. The second stage from 175 to $275^{\circ} \mathrm{C}$ results in a mass loss of $28.5 \%$ due to the PAMAM G3.0 dendrimer thermal decomposition and PEO chain breakage, and the maximal mass loss temperature at $200^{\circ} \mathrm{C}$. In the third stage of mass loss, $\mathrm{P}_{3}$ shows a rapid weight loss of $40.5 \%$ from 300 to $410^{\circ} \mathrm{C}$, corresponding to a spot of rudimental nucleus of the PAMAM dendrimer and PEO and the peak temperature at $392^{\circ} \mathrm{C}$. The results of $\mathrm{P}_{1}$ and $\mathrm{P}_{2}$ are almost
Table 2. TGA and DTG analysis of amphoteric PAMAM dendrimers

\begin{tabular}{|c|c|c|c|}
\hline Samples & $\begin{array}{c}\text { Temperature range } \\
{\left[{ }^{\circ} \mathbf{C}\right]}\end{array}$ & $\begin{array}{c}\text { Mass loss } \\
{[\%]}\end{array}$ & $\begin{array}{l}\mathbf{T}_{\max } \\
{\left[{ }^{\circ} \mathbf{C}\right]}\end{array}$ \\
\hline \multirow{2}{*}{ PAMAM G3.0 } & $25-160$ & 26.7 & \multirow{2}{*}{289} \\
\hline & $220-350$ & 55.7 & \\
\hline \multirow{3}{*}{$\mathrm{P}_{1}$} & $25-120$ & 10.0 & \multirow{3}{*}{213} \\
\hline & $175-275$ & 42.4 & \\
\hline & $300-410$ & 21.8 & \\
\hline \multirow{3}{*}{$\mathrm{P}_{2}$} & $25-120$ & 20.8 & \multirow{3}{*}{208} \\
\hline & $175-275$ & 33.5 & \\
\hline & $300-410$ & 24.7 & \\
\hline \multirow{3}{*}{$\mathrm{P}_{3}$} & $25-120$ & 11.3 & \multirow{3}{*}{392} \\
\hline & $175-275$ & 28.5 & \\
\hline & $300-410$ & 40.5 & \\
\hline
\end{tabular}

the same as $\mathrm{P}_{3}$. The data are presented in Table 2 . The thermal stability of $\mathrm{P}_{3}$ is more excellent than that of $\mathrm{P}_{1}$ and $\mathrm{P}_{2}$. It can be concluded from the experimental results that the chain length of PEO affects the thermal decomposition behavior of the amphoteric PAMAM dendrimers, and the longer chain length of PEO has a better thermal stability in nitrogen. This may be because the amphoteric PAMAM dendrimers peripheral terminated groups and linear PEO chains could form the dendritic sphericity architecture. On the one hand, efficiency of the charge adsorption produces aggregation intermolecular; on the other hand, the longer chain length of PEO is the easier twist among the peripheral dendrimers. Therefore the thermal stability is enhanced.

\subsection{Flocculation efficiency of the amphoteric PAMAM dendrimers}

Decolorizing rate $\left(d_{r}\right)$ of printing and dyeing wastewater disposed by the amphoteric PAMAM dendrimers are used to estimate their flocculating performances. The results for $\mathrm{P}_{1}, \mathrm{P}_{2}$ and $\mathrm{P}_{3}(\lambda=$ $454 \mathrm{~nm}$ ) are shown in Figure 3.

It can be seen from Figure 3a that an effective flocculation occurred when the flocculation system of amphoteric PAMAM dendrimers was used. The flocculation efficiency of $\mathrm{P}_{3}$ was superior to $\mathrm{P}_{1}$ and $\mathrm{P}_{2}$. One possible reason is that its molecule architecture is beneficial to bridge and charge neutralization coagulation. It has already been found that the combined use of the amphoteric PAMAM dendrimers and PAM can significantly enhance the flocculation efficiency. The flocculation results 

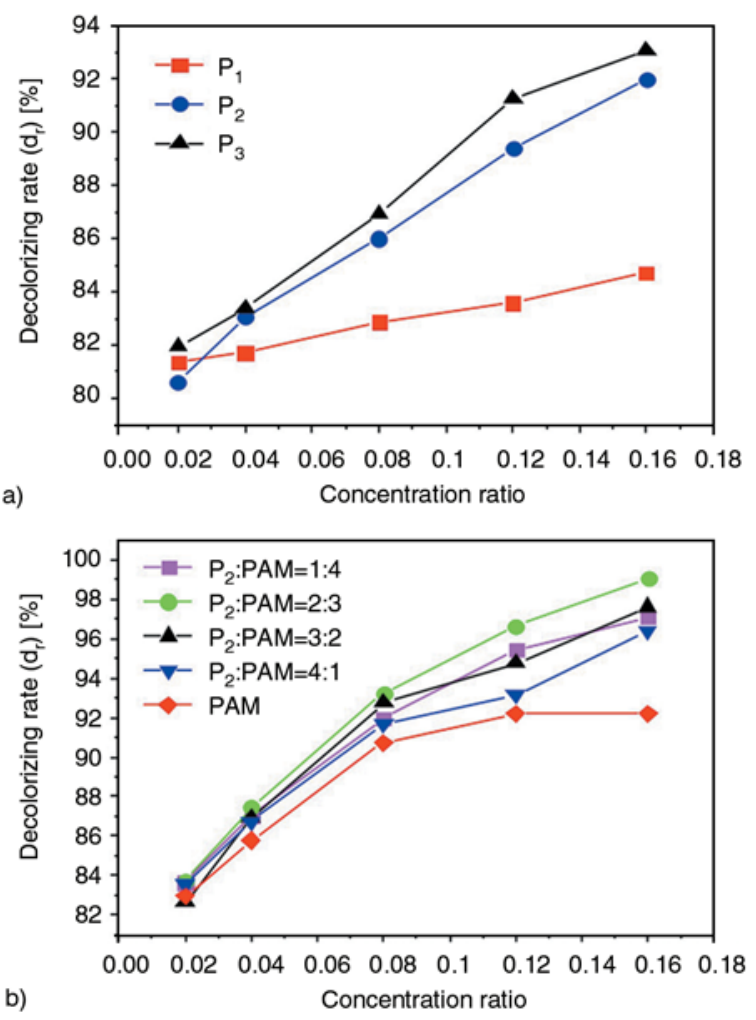

Figure 3. Decolorizing rate of flocculated wastewater disposed by a) $\mathrm{P}_{1}, \mathrm{P}_{2}$ and $\mathrm{P}_{3}$; b) a combination of $\mathrm{P}_{3}$ and $\mathrm{PAM}$ in different ratios; decolorizing rate: $d_{\mathrm{r}}=\left(1-A_{1} / A_{2}\right) \cdot 100 \%$, where $A_{1}$ is the absorbance of the flocculated wastewater and $A_{2}$ is the absorbance of the wastewater

obtained by the combination of $\mathrm{P}_{3}$ and PAM are shown in Figure $3 \mathrm{~b}$. It can be seen that higher flocculation efficiency is produced when the mass ratio of $\mathrm{P}_{3}$ and PAM is 2:3. The suggested flocculation mechanism may be that the amphoteric PAMAM dendrimers first create effective patches on the solid suspension of wastewater surface, and then PAM with high affinity to the particle surface makes bridges through those charged patches.

The other investigation is to determine the retention efficiency of the dendrimers as a retention aid in manual papermaking. The experiments were performed in a conventional manual papermaking procedure. The effects of retention rate for various mass fraction of retention aid are given in Figure 4. As can be seen in Figure 4a and $4 \mathrm{~b}$ an evident initial increase in retention rate $\left(r_{p u}\right)$ happens with increasing mass fraction of retention aid until the maximum value. Thereafter a decrease in retention rate occurs with increasing retention aid. A suitable mass fraction of retention aid is about $0.2 \% . \mathrm{P}_{3}$ shows the highest retention performance whose
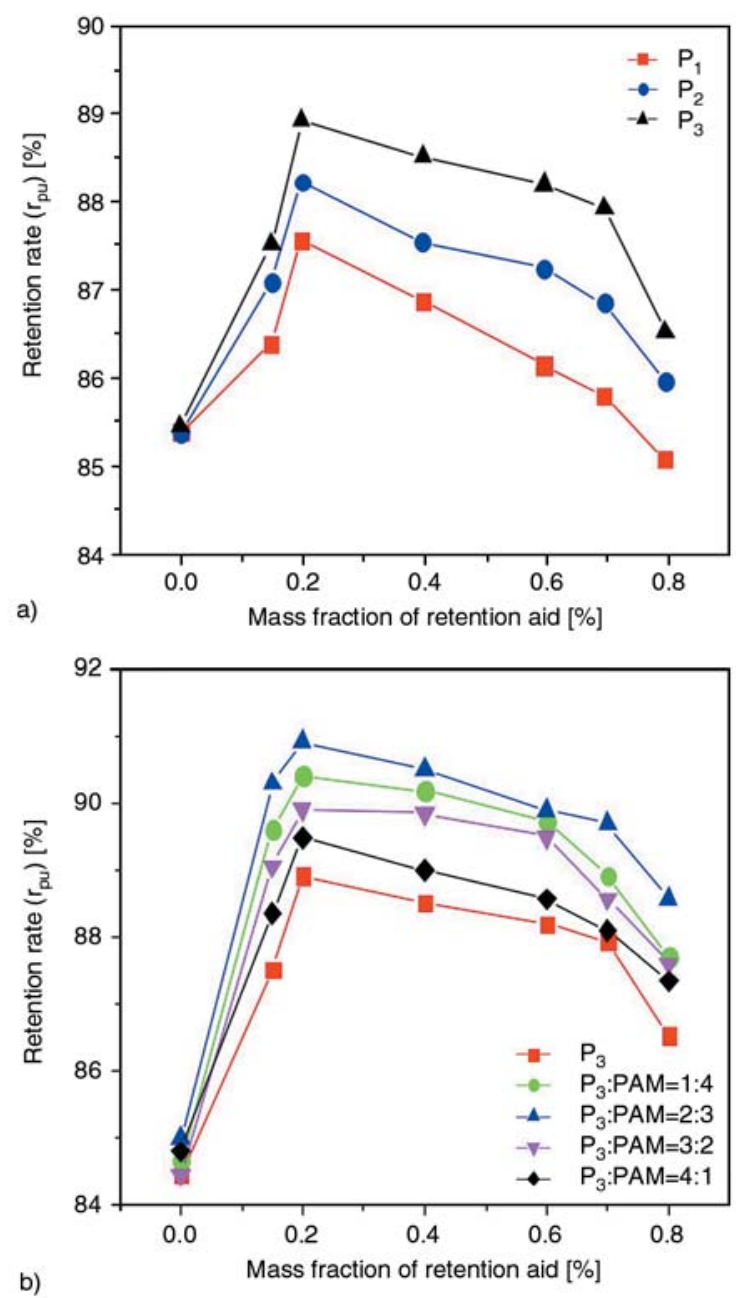

Figure 4. Effect of retention rate for various mass fraction of retention aid

retention rate achieves $89.4 \% . \mathrm{P}_{2}$ and $\mathrm{P}_{1}$ are about 88.2 and $87.5 \%$, respectively. The results clearly indicate that the longer chain length of PEO can induce the better retention efficiency. The retention rate can be significantly improved if the amphoteric PAMAM dendrimers are used in combination with PAM. The suitable mass ratio of $\mathrm{P}_{3}$ and PAM is $2: 3$, and the maximum value of retention rate reaches $90.9 \%$. All these effects can be explained by assuming that the amphoteric PAMAM dendrimers have particular molecule architecture, which has not only highly branched core-shell structure of dendrimers but also many long linear arms. The possible mechanism for this flocculation system is mainly through microparticle bridging in which fines or fillers can be captured and is subsequently swept up by the fibers. As a result, both the linear PAM and $\mathrm{P}_{3}$ which has a long chain of PEO into liquid to from more effective bridge, and thus give better retention efficiency. 


\section{Conclusions}

The amphoteric PAMAM dendrimers were synthesized based on Michael addition reaction of PAMAM G3.0 dendrimer with dimethylbenzylaminoethyl acrylate chloride (Bz80), sodium acrylic acid (SAA) and modified polyoxyethylene (MPEO) groups. FTIR, ${ }^{1} \mathrm{H}$ NMR, ${ }^{13} \mathrm{C}$ NMR and elemental analysis characterized the new dendrimers. These results demonstrated that the prepared dendrimers were composed of chain units of PAMAM G3.0, Bz80, SAA and MPEO. The exterior terminal groups of amphoteric PAMAM dendrimers were main cause to affect intrinsic viscosity, thermal stability and flocculation efficiency of the dendrimers. The flocculation efficiency of the amphoteric PAMAM dendrimers can be significantly improved by the combination of PAM. The dendrimers will have a potential application as a flocculant in wastewater treatment and as a new paper retention aid in papermaking.

\section{Acknowledgements}

The authors thank the project supported by Hunan Provincial Natural Science Foundation of China (project No.06JJ2067).

\section{References}

[1] Hecht S.: Functionalizing the interior of dendrimers: Synthetic challenges and applications. Journal of Polymer Science Part A: Polymer Chemistry, 41, 1047-1058 (2003).

DOI: $\underline{10.1002 / \text { pola. } 10643}$

[2] Tomalia D. A.: Birth of a new macromolecular architecture: Dendrimers as quantized building blocks for nanoscale synthetic polymer chemistry. Progress in Polymer Science, 30, 294-324 (2005). DOI: $10.1016 /$ j.progpolymsci.2005.01.007

[3] Vögt1e F., Gestermann R., Hesse H., Schwierz H., Windisch B.: Functional dendrimers. Progress in Polymer Science, 25, 987-1041 (2000). DOI: 10.1016/S0079-6700(00)00017-4

[4] Blaak R., Lehmann S., Likos C. N.: Charge-induced conformational changes of dendrimers. Macromolecules, 41, 4452-4458 (2008).

DOI: $10.1021 / \mathrm{ma} 800283 \mathrm{z}$

[5] Hendricks T. R., Dams E. E., Wensing S. T., Lee I.: Effects of catalyst introduction methods using PAMAM dendrimers on selective electroless nickel deposition on polyelectrolyte multilayers. Langmuir, 23, 7404-7410 (2007).

DOI: $\underline{10.1021 / 1 a 7007232}$
[6] Takahashi T., Kono K., Itoh T., Emi N., Takagishi T.: Synthesis of novel cationic lipids having polyamidoamine dendrons and their transfection activity. Bioconjugate Chemistry, 14, 764-773 (2003). DOI: $10.1021 / \mathrm{bc} 025663 \mathrm{f}$

[7] Wang S., Hong J. W., Bazan G. C.: Synthesis of cationic water-soluble light-harvesting dendrimers. Organic Letters, 7, 1907-1910 (2005). DOI: $\underline{10.1021 / \mathrm{ol} 047674 \mathrm{p}}$

[8] Mckee M. L.: Density functional theory study of anionic and neutral per-substituted 12-vertex boron cage systems, $\mathrm{B}_{12} \mathrm{X}_{12^{\mathrm{n}-}}(\mathrm{n}: 2,1,0)$. Inorganic Chemistry, 42, 1299-1305 (2002). DOI: $10.1021 / \mathrm{ic} 011021 \mathrm{c}$

[9] Fochi F., Jacopozzi P., Wegelius E., Rissanen K., Cozzini P., Marastoni E., Fisicaro E., Manini P., Fokkens R., Dalcanale E.: Self-sssembly and anion encapsulation properties of cavitand-based coordination cages. Journal of the American Chemical Society, 123, 7539-7552 (2001).

DOI: $\underline{10.1021 / \mathrm{ja} 0103492}$

[10] Kojima C., Kono K., Maruyama K., Takagishi T.: Synthesis of polyamidoamine dendrimers having poly(ethylene-glycol) grafts and their ability to encapsulate anticancer drugs. Bioconjugate Chemistry, 11, 910-917 (2000).

DOI: $\underline{10.1021 / \mathrm{bc} 0000583}$

[11] Kim T., Seo H. J., Choi J. S., Jang H. S., Baek J. U, Kim K., Park J. S.: PAMAM-PEG-PAMAM: Novel triblock copolymer as a biocompatible and efficient gene delivery carrier. Biomacromolecules, 5, 2487 2492 (2004). DOI: $10.1021 / \mathrm{bm} 049563 \mathrm{j}$

[12] Wang F., Bronich T. K., Kabanov A. V., Rauh R. D., Roovers J.: Synthesis and evaluation of a star amphiphilic block copolymer from poly( $\varepsilon$-caprolactone) and poly(ethylene glycol) as a potential drug delivery darrier. Bioconjugate Chemistry, 16, 397405 (2005).

DOI: $10.1021 / \mathrm{bc} 049784 \mathrm{~m}$

[13] Allen L., Polverari M.: Dendrimers: A new retention aid for newsprint, mechanical printing grades, and board. Nordic Pulp and Paper Research Journal, 15, 407-416 (2000).

DOI: 10.3183/NPPRJ-2000-15-05-p407-415

[14] Zhou G. Z., Tan H. M., Luo Y. J., Zhang X., Liao S. Q.: New method of TNT red-water treatment. Industrial Water Treatment, 6, 14-16 (2002).

[15] Mavredaki E., Neofotistou E., Demadis K. D.: Inhibition and dissolution as dual mitigation approaches for colloidal silica fouling and deposition in process water systems: Functional synergies. Industrial and Engineering Chemistry Research, 44, 7019-7026 (2005). DOI: $10.1021 / \mathrm{ie} 0501982$ 
[16] Demadis K. D., Neofotistou E.: Synergistic effects of combinations of cationic polyaminoamide dendrimers/anionic polyelectrolytes on amorphous silica formation: A bioinspired approach. Chemistry of Materials, 19, 581-587 (2007).

DOI: $10.1021 / \mathrm{cm} 062370 \mathrm{~d}$

[17] Demadis K. D., Neofotistou E., Mavredaki E., Tsiknakis M., Sarigiannidou E-M., Katarachia S. D.: Inorganic foulants in membrane systems: chemical control strategies and the contribution of 'green chemistry'. Desalination, 179, 281-295 (2005). DOI: 10.1016/j.desal.2004.11.074
[18] Peng X. C., Peng X. H., Zhao J. Q., Lin Y. W., Wang Q. T.: Preparation and characterization of novel PAMAM 4.0G-DMC cationic dendrimer and its flocculating and dewatering performances. Petrochemical Technology, 34, 986-989 (2005).

[19] Peng X. C., Peng X. H., Zhao J. Q.: Preparation and characterization of a polyoxyethlene-macromonomer modified polyamidoamine dendrimers. Nanoscience, 1, 146-149 (2005).

[20] Yamakawa H.: Modern theory of polymer solution. Harper and Row, New York (1971).

[21] Long F., Fan Y., Ding H. J., Jia X. R., Li M. Q.: The intrinsic viscosity of polyamidoamine dendrimer. Chemical Journal of Chinese Universities, 20, 16281632 (1999). 